Gazi University
Journal of Science
$\mathrm{http} / /$ dergipark.gov.tr/gujs

\title{
Visual Impact and Potential Visibility Assessment of Wind Turbines Installed in Turkey
}

\author{
Mehmet BILGILI ${ }^{1, *(1)}$, Hakan ALPHAN ${ }^{2}$ (D) \\ ${ }^{I}$ Cukurova University, Ceyhan Engineering Faculty, Department of Mechanical Engineering, 01950 Adana, Turkey \\ ${ }^{2}$ Cukurova University, Architecture Faculty, Department of Landscape Architecture, 01330 Adana, Turkey \\ Highlights \\ - Recent growth of wind power generation in Turkey was evaluated. \\ - Development of commercial wind turbine technology was discussed in detail. \\ - Potential visibility analysis for existing wind power plants was performed.
}

Article Info

Received: 16 Oct 2020

Accepted: 05 Apr 2021

\section{Keywords}

Landscape

Potential visibility

Wind energy

Wind turbine technology

Turbine size

\begin{abstract}
Global installed wind power capacity has risen nearly 4.3 times in the last decade, from 120.7 GW in 2008 to more than $591 \mathrm{GW}$ in 2018. On the other hand, installed wind power capacity in Turkey was reported as $7.37 \mathrm{GW}$ in 2018 , and it is scheduled to reach $12 \mathrm{GW}$ in 2023 . The aim of this paper is to assess the recent growth of wind power generation in Turkey in terms of power generation technologies, wind power potential, techno-economic feasibility, and visibility of onshore wind turbines. In this respect, several metrics such as cumulative installed wind power capacity $(\mathrm{MW})$, total number of turbines, total swept area of turbines $\left(\mathrm{km}^{2}\right)$, total hub height of turbines $(\mathrm{km})$, number of the turbine per turbine power capacity $(1 / \mathrm{GW})$, swept area per turbine power capacity $\left(\mathrm{m}^{2} / \mathrm{MW}\right)$ and hub height per turbine power capacity $(\mathrm{m} / \mathrm{MW})$ are developed to assess wind power generation regionally between the years of 2010 and 2018. Results show that wind power generation capacity is on the rise in Turkey. But this growth also implies an increase in the number and size of turbines. Eventually, turbines with higher hubs and rotor diameters have become more abundant and visible in landscapes.
\end{abstract}

\section{INTRODUCTION}

Energy is one of the vital requirements of the contemporary world. It has an unquestionable critical role in technological development development and economic progress that directly influences the quality and comfort of human life [1,2]. It is widely considered that energy is not only an indispensable requirement for the internal dynamics of countries but also it is a strategic issue that sometimes causes political debates and even military conflicts [3]. Recently, global energy demand has increased remarkably due to emerging technologies, population growth, and declining resources of fossil fuels. In this respect, global warming, efficient use of energy sources and greenhouse gas (GHG) emissions resulting from fossil energy consumption have become the most attractive issues in the present decade [4-7].

The increase in energy demand is mostly due to improved living standards, industrial development, and population growth in developing countries. In this respect, it is expected that the total energy demand will increase by $21 \%$ by 2030 . Besides, growing concerns over climate change urge governments worldwide to search for alternative sources of energy [8]. Recently, energy-related $\mathrm{CO}_{2}$ emissions have risen worldwide. In line with this trend global emissions are expected to rise the average global temperature around $6{ }^{\circ} \mathrm{C}$ in a long period. Increased emissions of GHGs result in an increase of further heating and severity of the related concerns [9]. The International Energy Agency (IEA) estimates that worldwide energy-related $\mathrm{CO}_{2}$ emissions will increase by approximately $50 \%$ by 2030 unless current policies change. In addition, there will be a $40 \%$ increase in oil demand [10] and fossil fuels will continue to meet the vast majority of the 
world's growing energy demand. By the year of 2050, the energy-based production of $\mathrm{CO}_{2}$ is projected to be more than double, and concerns over the security of supplies will be heightened by the increased oil demand [11]. According to the IEA, global $\mathrm{CO}_{2}$ emissions are expected to increase from $35.9 \mathrm{Gt}$ in 2014 to $42 \mathrm{Gt}$ by 2030 . Growth in $\mathrm{CO}_{2}$ emissions will continue, and $\mathrm{CO}_{2}$ emissions will probably reach $57 \mathrm{Gt}$ in the year of 2050 [12]. Because of this reason, a global revolution should be required in ways that energy is supplied and used. Renewable energy sources, low-carbon energy technologies, nuclear power, energy-efficient systems, carbon capture and storage, and new transportation technologies are required in order to achieve $50 \%$ reduction in the current level of $\mathrm{CO}_{2}$ emissions by 2050 in order to restrict global temperature rise with $2^{\circ} \mathrm{C}$ by 2050 above pre-industrial levels [11]. Among these technologies, wind energy sources have a crucial role [13].

Renewable energy offers cost-effective opportunity and distinctive options compared with conventional power generation technologies, both in developed and developing countries [14-16]. Wind power technology is growing rapidly worldwide. The advantages of wind power in terms of reasonable costs of energy production and competitiveness make its investment appealing globally [17]. Wind power is in the trend of expanding worldwide, and also reflects the reduced cost of turbines, widening policy support, and thriving of the investor recognition of the positive characteristics of wind generation [18]. As known, wind energy undoubtedly offers significant advantages in terms of environment and cost. However, it also has some disadvantages, such as high initial costs, threats to wildlife, noise disturbance, and visual impacts. The visual and environmental impacts of wind turbines strongly influence their public acceptance. Although wind turbines come with eye-catching designs, they have strong impacts on the visual characteristics of landscapes. Growing numbers and sizes of turbines may become dominant in landscapes and as they dominate the views from settlements and roads and reduce scenic quality.

Numerous industrialized countries have supported to find new energy resources by legislations, in addition to lowering the taxes or performing privileged taxing system, amongst other measures. For instance, considering each member European Union is required to gain a compulsory of $20 \%$ share of renewable energy sources in their whole energy demand by the year of 2020. For this purpose, a new law was implemented by Turkey in 2010 where cost, time, and payments were determined inside the concept of the principles of "Wind Power Plant Supporting Mechanisms" [13]. At the present time in Turkey, the wind power potential is $48 \mathrm{GW}$, however, the installed wind power capacity is $7.37 \mathrm{GW}$ by the end of 2018 , and it is scheduled to reach $20 \mathrm{GW}$ in 2023. Parallel to this development, to minimize visual effects in the siting of wind facilities is a substantially important issue for land management agencies. The visual effect is a visible feature of a wind farm on a slope or ridge line as a landscape [19-23]. The minimization of visual effects in the siting of wind facilities is a substantially important issue for land management. Wind turbines undoubtedly change the landscape character. People's perceptions about wind farms are various. While some people stand against the character changes in landscapes brought by a wind farm, others think that landscape character is enriched by wind turbines [24-29].

Wind turbines have a very special landscaping effect [30-34], due to the fact that they are tall and visually dominant objects in landscapes. Rotation of the blades has also attracted particular attention in the scenery. However, wind turbines are dependent on consistent wind conditions, which generally occurs in open landscapes such as mountain ridges that are visible from many different locations and that are attractive for their scenic quality. It is quite clear that wind power generation has a strong positive impact on the economy as well as on local and regional development. But it is also important to consider the fact that wind turbines have impacts on the visibility of landscapes. Therefore, site selection procedures for wind power generation may be optimized given the visibility of these structures in landscapes is also considered as a factor. The effect of wind turbines on the visual properties of the landscape can be divided into landscape effects and visual effects, which are very different but interconnected. In the context of preliminary planning, visual effects refer to the potential of direct visual blockage from specific viewpoints in a wind power plant, while landscape effects include the changes in perception of structure, visual character, and wider landscape quality. This paper deals with the development of wind power generation and takes some metrics such as 
hub height, rotor swept area, and the number of turbines as visibility metrics. The main assumption here is that any increase in these metrics results in higher visibility.

Site-selection for industrial wind power generation to minimize the visual impact to high-value natural resources shows great importance for land management of wind power generators and the visual contrasts that they cause in landscapes depend on the complex interactions of various factors. Therefore comprehensive studies on the visibility of these structures in landscapes are required. In recent years, interest and research based on this subject have been increasing considerably in environmental planning. To assess the visual impact of wind turbines, Wrozynski et al. [35] proposed a new method related to the GIS tools and 3D graphic software for developing three-dimensional models and computer animations. Maehr et al. [36] discussed how a methodology using emotional self-assessments and photo manipulations can help to predict the emotional response to the visual impact on the landscape at the projection design for new wind turbine installations. Minelli et al. [37] presented the development of the Open Source GIS tool as a method to quantitatively assess the visual impact of and wind and solar power facilities using line-ofsite techniques. Skenteris et al. [38] applied the hedonic pricing method (HPM) in environmental economics to determine quantitatively the environmental effect of large-scale development of wind power at the local level. Bernetti et al. [39] proposed some design strategies to reduce the visual impact of wind turbines and to determine the changes to the landscape created by wind turbines. Corry [40] analyzed the visual impact for 45 wind turbines by comparing them with the post-development conditions of the wind energy landscape. Lothian [41] conducted a research on the visual impact and public acceptance of wind farms in Australia. Abromas et al. [42] discussed the importance, nature, and degree of contrast of the visual impact of wind turbines in Kretinga area by evaluating the impact of the wind turbines on the landscape when observing them from the selected observation place.

As seen from the literature study, to date, very few studies related to the visual impact and potential visibility assessment of wind turbines in Turkey have been realized. For this reason, this study assesses the short-term development of wind power generation in Turkey in terms of technological development, wind power potentiality, techno-economic feasibility, and visual impact. The novelty and contributions of this study mainly are as follows: (i) presenting a deep study and review about the wind power development in Turkey, (ii) presenting very valuable information related to the wind power generation to acquire an overall vision of the country's evolution and the current situation, (iii) assessing the potential visibility of wind turbine technology in Turkey for the decision-making process for new wind farms proposals, (iv) investigating and analysing the growth in scale of wind turbines in Turkey.

\section{METHODOLOGY}

A typical horizontal axis wind turbine (HAWT) and some turbine visibility variables are presented in Figure 1. Evaluation of the aesthetic effects of wind turbines is a complex issue as, in most cases, it refers to the societal and perceptional issues. However, visibility and visual impact are more straightforward as they are conceptualized by quantitative and geospatial analyses. Visibility and visual impact assessments are often related to the following variables [20]: 


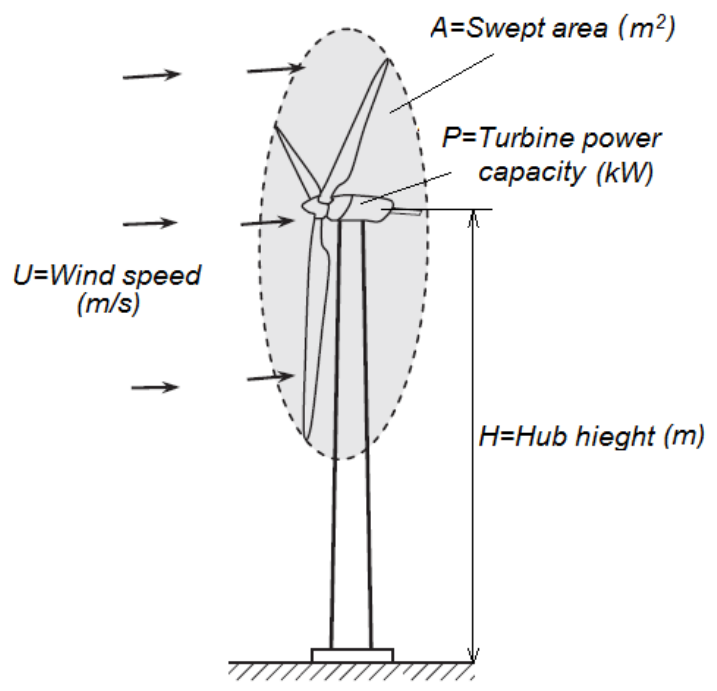

Figure 1. A typical HAWT and its primary potential visibility parameters

- Number of turbines,

- Size/height or hub height of turbines,

- Distance to the wind turbines, or proximity of residential and recreational activities,

- Arrangement of wind turbines - visibility of wind turbines from different points of view,

- Total area of the farm,

- Density of turbines,

- Traveling time or road length affected by the view of wind turbines,

- Colouring of turbines,

- Change of the background attributes,

- Houses or area affected by the view of wind turbines,

- Distribution of population affected by the view of wind turbines,

- Number of wind power plants,

- Rotor swept area,

- Continuity - meaning the "number of turns in the silhouette",

- Contrast,

- Lightness,

- Climate,

- Movement - moving or stationary blades,

- Observers height,

- Weather, or atmospheric conditions,

- Open view to the turbines,

- Forest cover,

- Built environment.

Of these variables, number of turbines, total rotor swept area, total hub height are taken into consideration. These variables are also used for "per power category" calculations. In addition, total turbine power is calculated.

\subsection{Total Power Capacity of Turbines}

Power output from the wind turbine $\left(P_{\text {out }}\right)$ and turbine power coefficient $\left(C_{P}\right)$ can be usually defined as:

$$
P_{\text {out }}=\frac{1}{2} \rho U^{3} A C_{p}(W)
$$




$$
\begin{aligned}
& C_{p}=P_{\text {out }} /\left(0.5 \rho U^{3} A\right) \\
& C_{p}=4 a(1-a)^{2}
\end{aligned}
$$

where $A\left(\mathrm{~m}^{2}\right)$ is the rotor swept area, $U(\mathrm{~m} / \mathrm{s})$ is the wind speed, $\rho\left(\mathrm{kg} / \mathrm{m}^{3}\right)$ is the atmospheric air density and $a$ is the flow induction factor. In a wind turbine, when the wind speed increases over the cut-in velocity, the wind turbine starts to rotate and produces electrical energy. Typically, at a speed where the wind speed is between 12 and $17 \mathrm{~m} / \mathrm{s}$, the wind turbine power achieves the limits that the electric generator is capable of $[43,44]$. At the generator output, this limit is called the rated (nominal) power output or wind turbine power capacity. For wind turbines installed in any region, the total power capacity of turbines $(P, M W)$ is defined as the sum of the rated power outputs of the turbines, and it can be expressed as:

$$
P=\left(\sum_{i=1}^{n} P_{i}\right)(M W)
$$

Here, $P_{i}$ is the $i$ th observation in the installed wind turbines.

\subsection{Total Number of Turbines}

Total number of turbines $(N)$ is defined as the sum of the wind turbines installed in any region, and it can be calculated as:

$$
N=\left(\sum_{i=1}^{n} N_{i}\right)
$$

Here, $N_{i}$ is the $i$ th observation in the installed wind turbines.

\subsection{Total Rotor Swept Area of Turbines}

The blade swept area can be calculated as:

$$
A=\pi\left[(l+r)^{2}-r^{2}\right]=\pi l(l+2 r)\left(m^{2}\right)
$$

where $l(m)$ is the length of wind blades and $r(m)$ is the radius of the hub. For wind turbines installed in any region, total rotor swept area of turbines $\left(A, \mathrm{~km}^{2}\right)$ can be calculated as:

$$
A=\left(\sum_{i=1}^{n} A_{i}\right)\left(k m^{2}\right) .
$$

Here, $A_{i}$ is the $i$ th observation in the installed wind turbines.

\subsection{Total Hub Height of Turbines}

For wind turbines installed in any region, total hub height of turbines $(\mathrm{H}, \mathrm{km})$ can be calculated as:

$$
H=\left(\sum_{i=1}^{n} H_{i}\right)(k m) .
$$

Here, $H_{i}$ is the $i$ th observation in the installed wind turbines. 


\subsection{Number of the Turbine Per Power Capacity}

Considering main potential visibility parameters of wind turbines installed in any region, number of the turbine per power capacity $(\dot{N}, 1 / G W)$ is the ratio of the total number of turbines $(N)$ to the total power capacity of turbines $(P)$. It can be calculated as;

$$
\dot{N}=\left(\sum_{i=1}^{n} N_{i}\right) /\left(\sum_{i=1}^{n} P_{i}\right)\left(\frac{1}{G W}\right) .
$$

\subsection{Rotor Swept Area Per Power Capacity}

For wind turbines installed in any region, rotor swept area per power capacity $\left(\dot{\mathrm{A}}, m^{2} / M W\right)$ is the ratio of the total rotor swept area of turbines $(A)$ to the total power capacity of turbines $(P)$. It can be calculated as;

$$
\dot{A}=\left(\sum_{i=1}^{n} A_{i}\right) /\left(\sum_{i=1}^{n} P_{i}\right)\left(\frac{m^{2}}{M W}\right)
$$

\subsection{Hub Height of the Turbine Per Power Capacity}

Considering main potential visibility parameters of wind turbines installed in any region, hub height of the turbine per power capacity $(\dot{H}, m / M W)$ is the ratio of total hub height of turbines $(H)$ to the total power capacity of turbines $(P)$. It can be calculated as;

$$
\dot{H}=\left(\sum_{i=1}^{n} H_{i}\right) /\left(\sum_{i=1}^{n} P_{i}\right)\left(\frac{m}{M W}\right) .
$$

\section{RESULTS AND DISCUSSION}

\subsection{Global Renewable Electric and Wind Power Capacities}

Renewable energy sources (RESs) have overgrown in recent years. They have the potential to develop and expand significantly all over the world as sustainable energy resources [1]. As of early 2016, more than 164 countries have aimed to establish targets on renewable energy, and around 145 countries have legalized renewable energy support policies [45]. A wide range of renewable energy alternatives exist. These include direct or indirect energy extraction from the sun, wind or the heat stored deep in the earth. Ocean waves and tides, hydropower, biomass, liquid biofuels, solid biomass, and biogas are other sources of energy [1]. Globally, growing public awareness enhances the development progress of renewable energy systems [45]. Figure 2 shows the development of the total installed renewable power capacity in the world. As can be seen from the figure, the total installed renewable energy capacity in the world has developed rapidly over the years. Worldwide progress of renewable energy started in the 1990s and it kept rising profoundly in the 2000s. Then, power generation technologies as well as installed capacity have risen profoundly. In 2007, $1,000 \mathrm{GW}$ of renewable capacity was installed, and currently total capacity has reached 2,378 GW worldwide. 


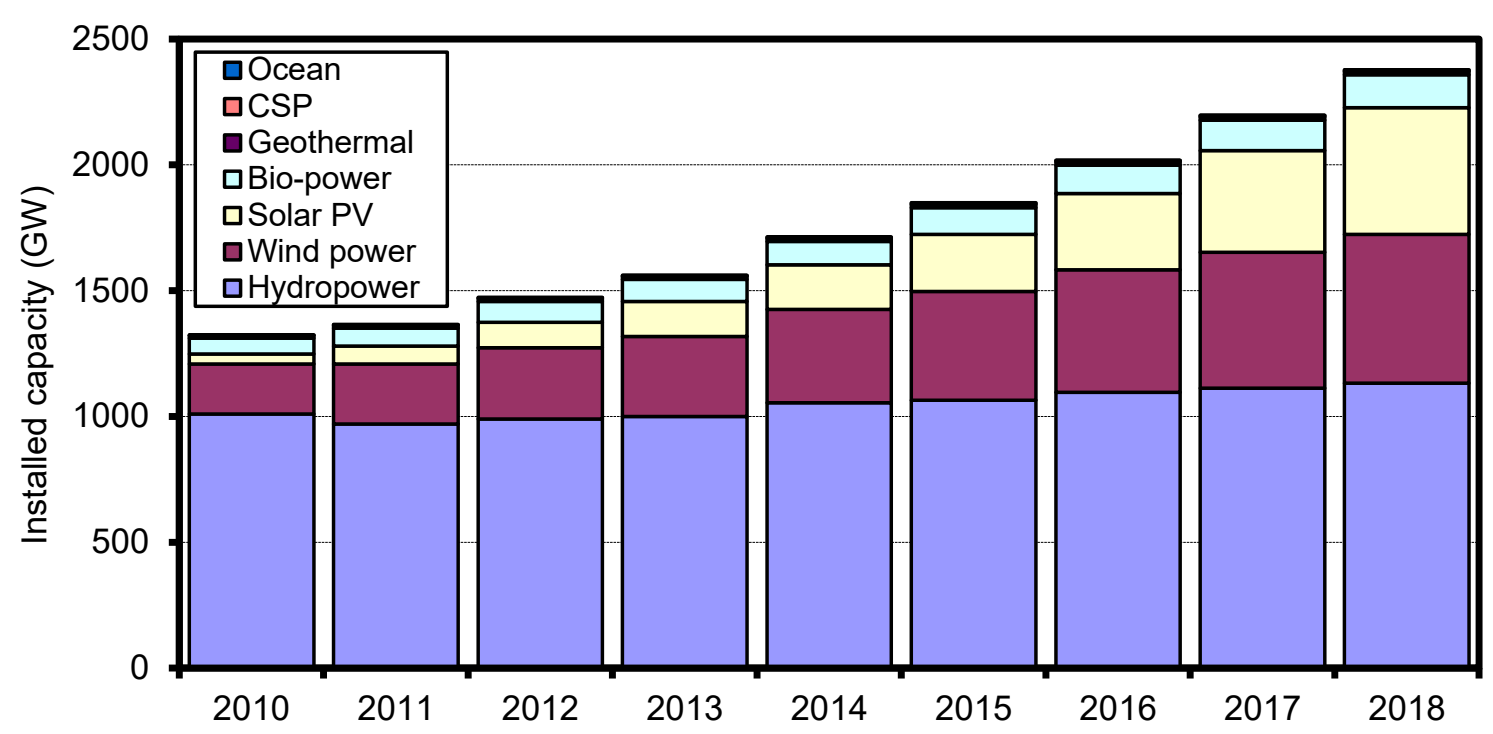

Figure 2. The development of the total installed renewable power capacity in the world

Figure 3 presents the renewable energy share of global electricity generation. In general, RESs record global growing share of electric capacity invested yearly. By the end of 2018, it is estimated that RESs and wind power made up $26.2 \%$ and $5.5 \%$ of global electric production. Several countries are now keen on producing electricity from variety of RESs and they have already achieved high capacity levels. For instance, contributions of renewable power generation were realized as $51 \%$ in Denmark, 36\% in Uruguay, 29\% in Ireland, 26\% in Germany and 24\% in Portugal in 2018. China, the United States, Germany, Japan and India were qualified to be the leading producers for cumulative installed renewable electric capacity at the end of 2018. China is home to nearly $30 \%$ of the world's renewable power capacity, totaling approximately $727 \mathrm{GW}$, including about $322 \mathrm{GW}$ of hydropower. The leading countries for nonhydro power capacity are especially China, the United States and Germany followed by India, Japan and United Kingdom which all completed the year with parallel capacity levels [45].

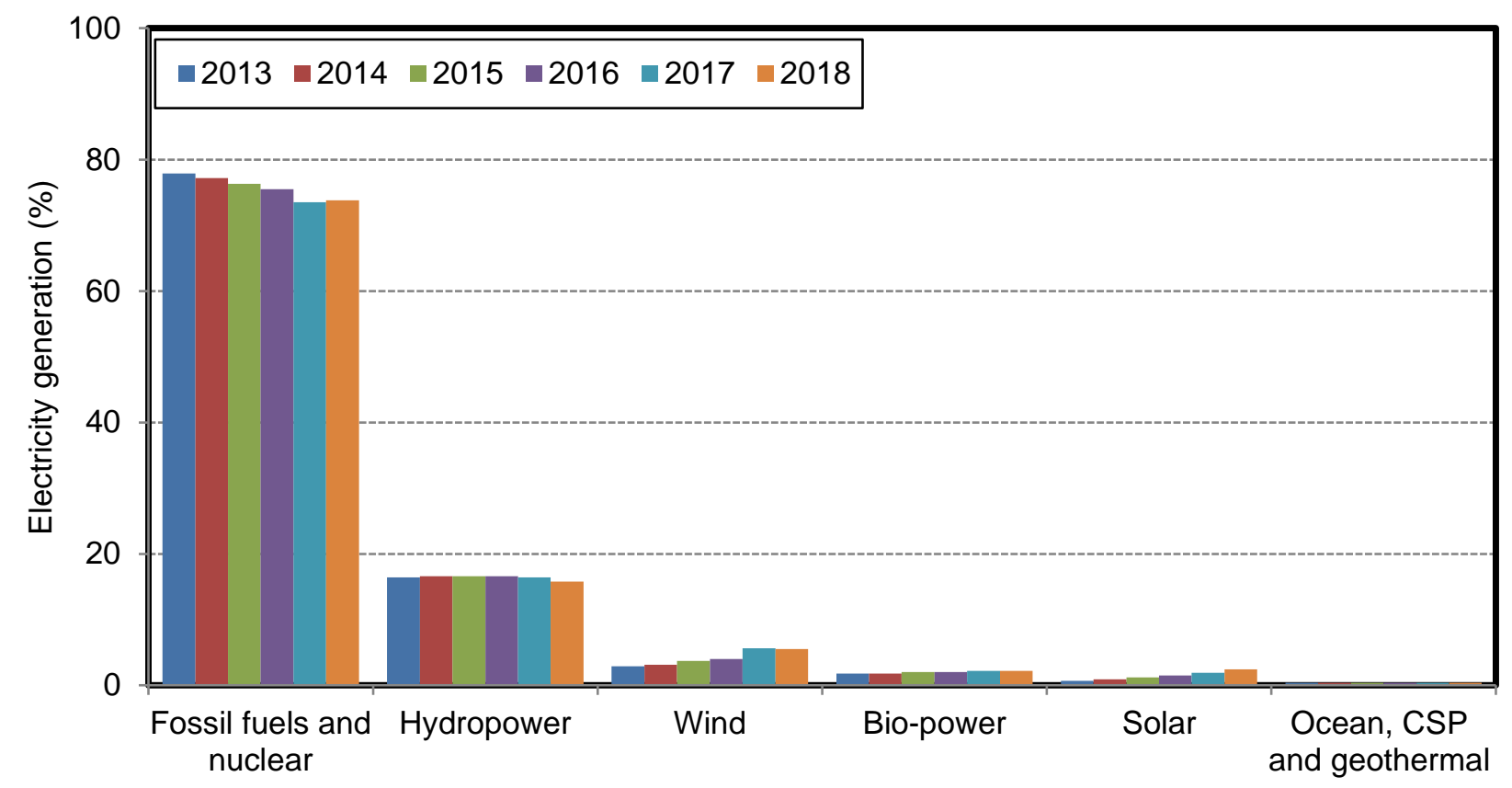

Figure 3. Renewable energy share of worldwide electricity generation

Wind power has been growing as a reliable and competitive electric producing technology. This technology continues to grow with more active countries and manufacturing companies, and thus, the global annual 
installed capacity increases rapidly with new investments. Technological progress has continuously reduced energy costs, especially for offshore [11]. The wind industry employs 1.16 million people worldwide, up relative to 2017. Main portions of employments have been particularly taken by China and the United States. In addition, Germany, India, Brazil and the European Union experience in moderate level of employments [45]. Similar to the most RESs, wind power is capital-intensive, and declining of capital costs is important for realization of wind power projects. Although fuel costs aren't valid for wind operations, however it is proper to lower the operation and maintenance expenses for improving the economy of wind power. Recently, the initial investments of wind farm are reduced, mainly competition between producers and technological advancements which is enhanced wind turbine capacity factors [45]. The global weighted average levelised cost of electricity (LCOE) of onshore wind farm in 2017 was 0.06 $\mathrm{USD} / \mathrm{kWh}$, while for offshore wind farm, it was $0.14 \mathrm{USD} / \mathrm{kWh}$. Some countries have held out financial supports like feed-in tariffs to keep in safe the greater income and to reduce investor risk [18].

Wind power production was succeeded in the UK and the US in 1887-1888. Nevertheless, modern wind power is said to have commenced in Denmark, where horizontal-axis wind turbines were constructed in Askov in 1891, and a $22.8 \mathrm{~m}$ wind turbine to generate electricity started its operation in 1897. After that, energy generation from wind has widened from Europe and the US to the world. Global installed wind generation capacity has enhanced nearly 70 times in the last two decades, from $7.5 \mathrm{GW}$ in 1997 to more than $540 \mathrm{GW}$ in 2018 [18]. Nowadays, for electricity generation wind power is the fastest growing sector and, it has also been seen that the wind power is the fastest growth among RESs in recent years [4]. Figure 4 indicates the total wind power installed capacity in Europe and the world between 2010 and 2018. The capacity of wind energy installation within this given interval has a rapid increasing trend. The total installed wind power capacity in 2010 was $197.96 \mathrm{GW}$ globally. The total worldwide wind power capacity at the end of 2018 was $591 \mathrm{GW}$. A $51 \mathrm{GW}$ of energy capacity is installed by the global wind power industry in 2018 [46]. Presently, the EU owns $178.8 \mathrm{GW}$ of installed wind power capacity.

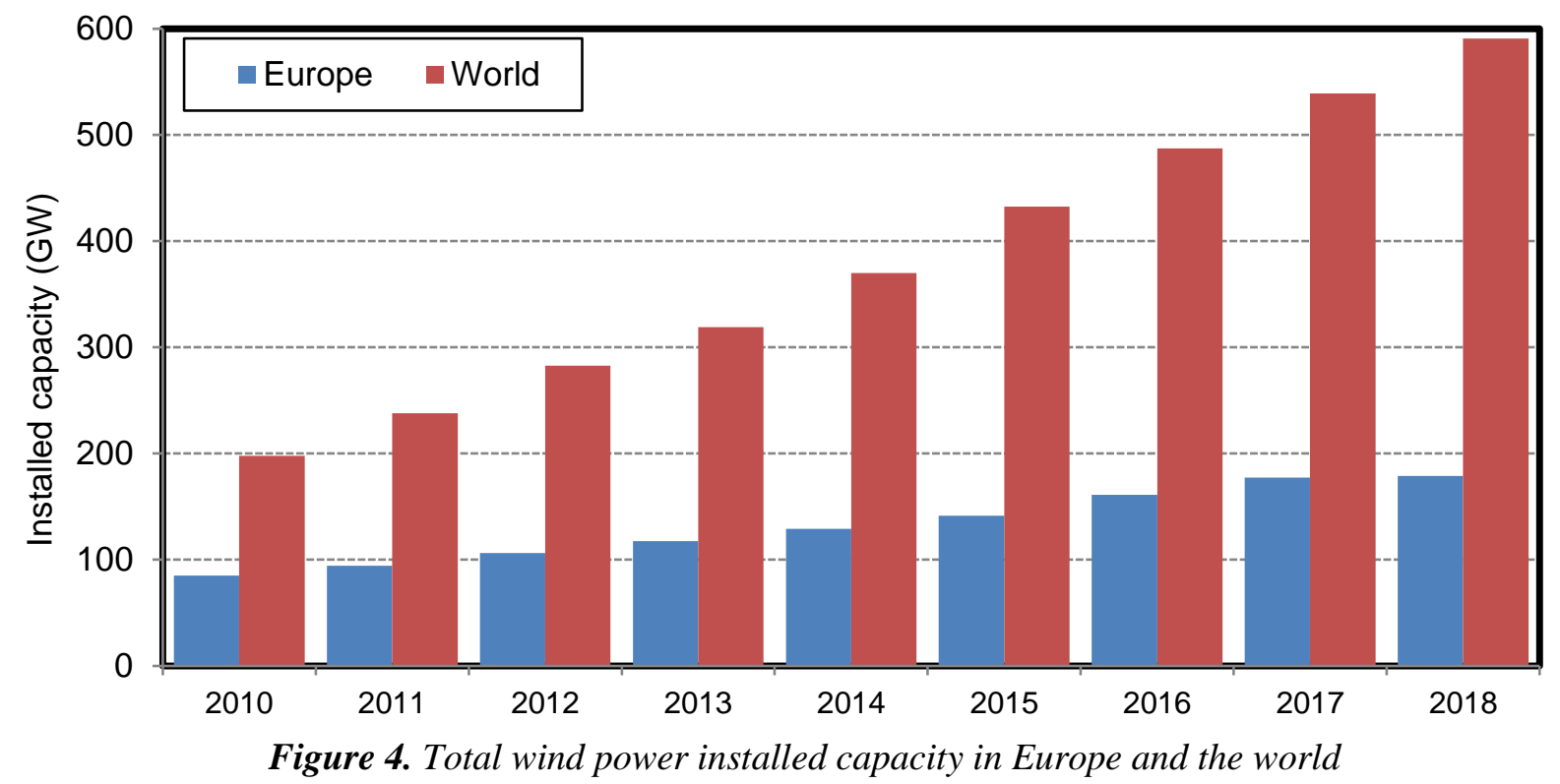

\subsection{Wind Power Capacity of Turkey}

It is known that Turkey is the one of the developing countries in Europe and is situated in between Asia and Europe having a larger part in Anatolia and the other part in southeastern Europe, where it is bordered by the Mediterranean Sea, the Aegean Sea, and the Black Sea [47-49]. Turkey's economy is the $18^{\text {th }}$ best economy in the world and it is regarded to be a developing country. Needs for electrical energy in Turkey have been continuously enhanced due to the increase of population and growing of the economy. Parallel to these developments, Turkey's $\mathrm{CO}_{2}$ emissions based on energy demands continue to increase. The $\mathrm{CO}_{2}$ concentration increased from 44.85 Mt to 402.8 Mt from 1970 to 2016, respectively. 


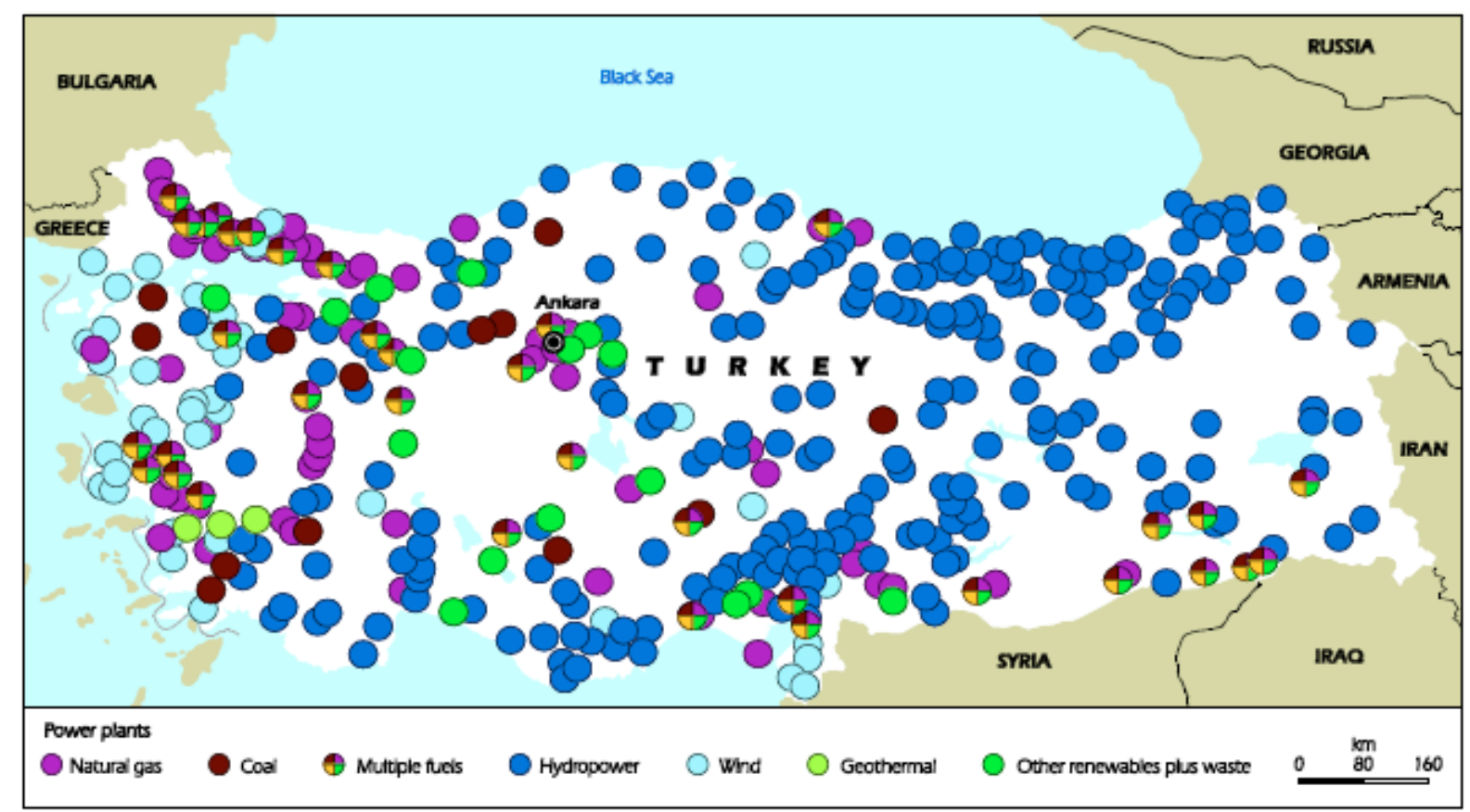

Figure 5. Location of electricity generation plants in Turkey [50]

Figure 5 presents the location of electricity generation plants in Turkey [50]. Figure 6 shows the share of electricity generation in Turkey. It is obvious from the figures; electric energy in Turkey is generated from power stations such as thermal, hydro, wind, geothermal and solar types. However, there is yet no used nuclear power for electric production. Thermal and hydro powers are the most rapid growing installed capacities in the country. However, geothermal, solar and wind powers are comparatively small installed capacities. Turkey's total installed electricity production capacity and the total electricity production were only $33 \mathrm{MW}$ and $45 \mathrm{GWh}$, respectively by the year of foundation of Republic of Turkey in 1923 [46]. But, Turkey's total electricity generation came up to 303.9 TWh in 2018. Keeping the electricity generation of 2018 in view, thermal power plants' share was $68.5 \%$. Hydro and wind accounted for $19.8 \%$ and $6.6 \%$, respectively. Currently, the Turkish market has a large natural gas and crude oil pipelines and other similar projects under negotiations. A total installed electric generating capacity of about $10 \mathrm{GW}$ is estimated to be attained in coming ten years according to the current regulatory framework, but this may even become $20 \mathrm{GW}$ with the amendments to the regulatory framework as interpreted by the Turkish Wind power Association. Turkey being one of the primary participants in the wind power market of the EU became the $4^{\text {th }}$ largest annual market in 2017 [46]. Because of the limited oil and gas reserves, Turkey is rapidly changing its direction towards renewable energy sources for improving precaution against energy shortages, searching ways to gain $30 \%$ of its electricity demands from renewable energy sources by the year of 2023. However, Turkey needs wide range of investments in order to meet continuously growing energy demand [46]. 


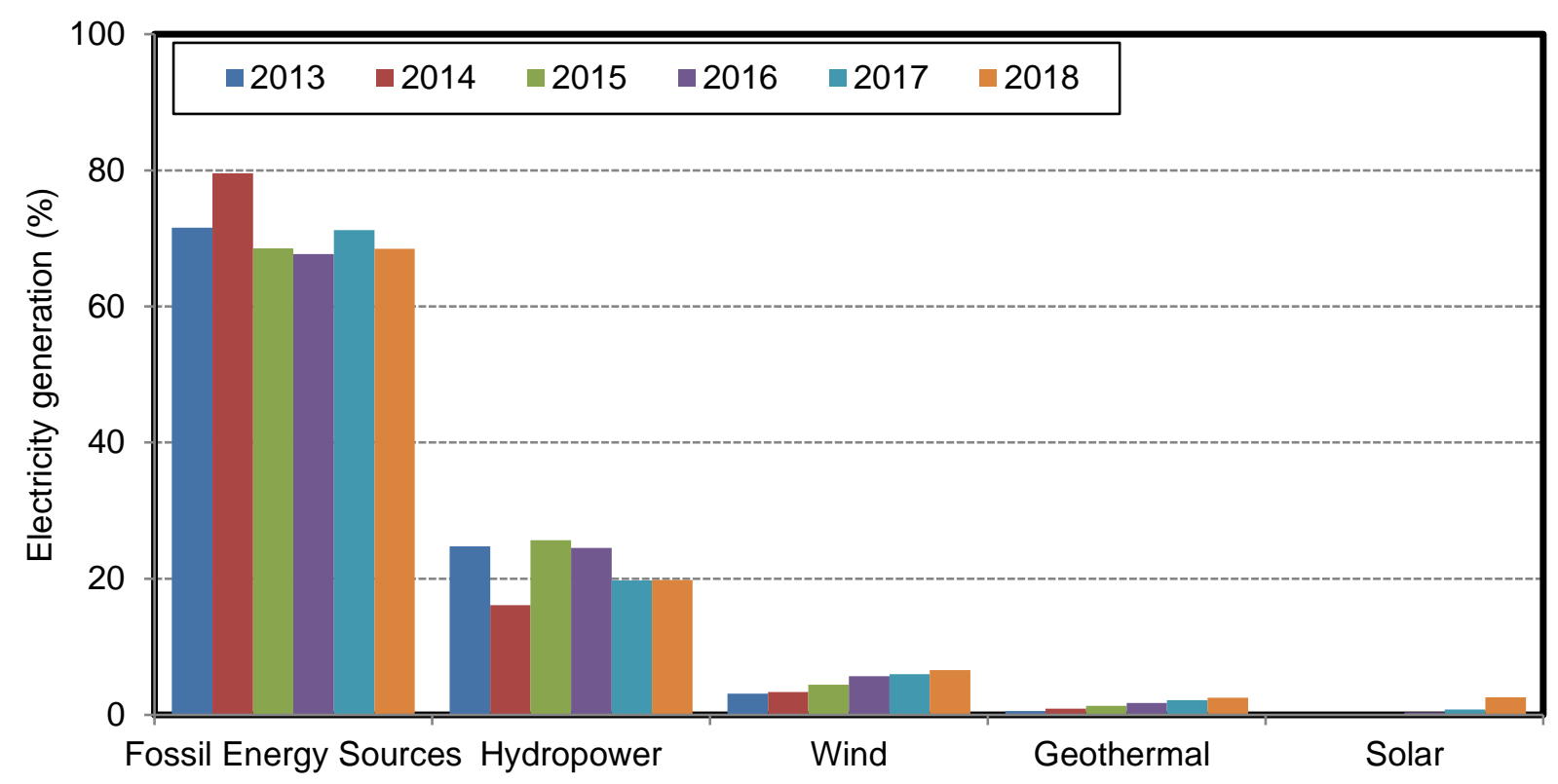

Figure 6. The share of electricity generation in Turkey

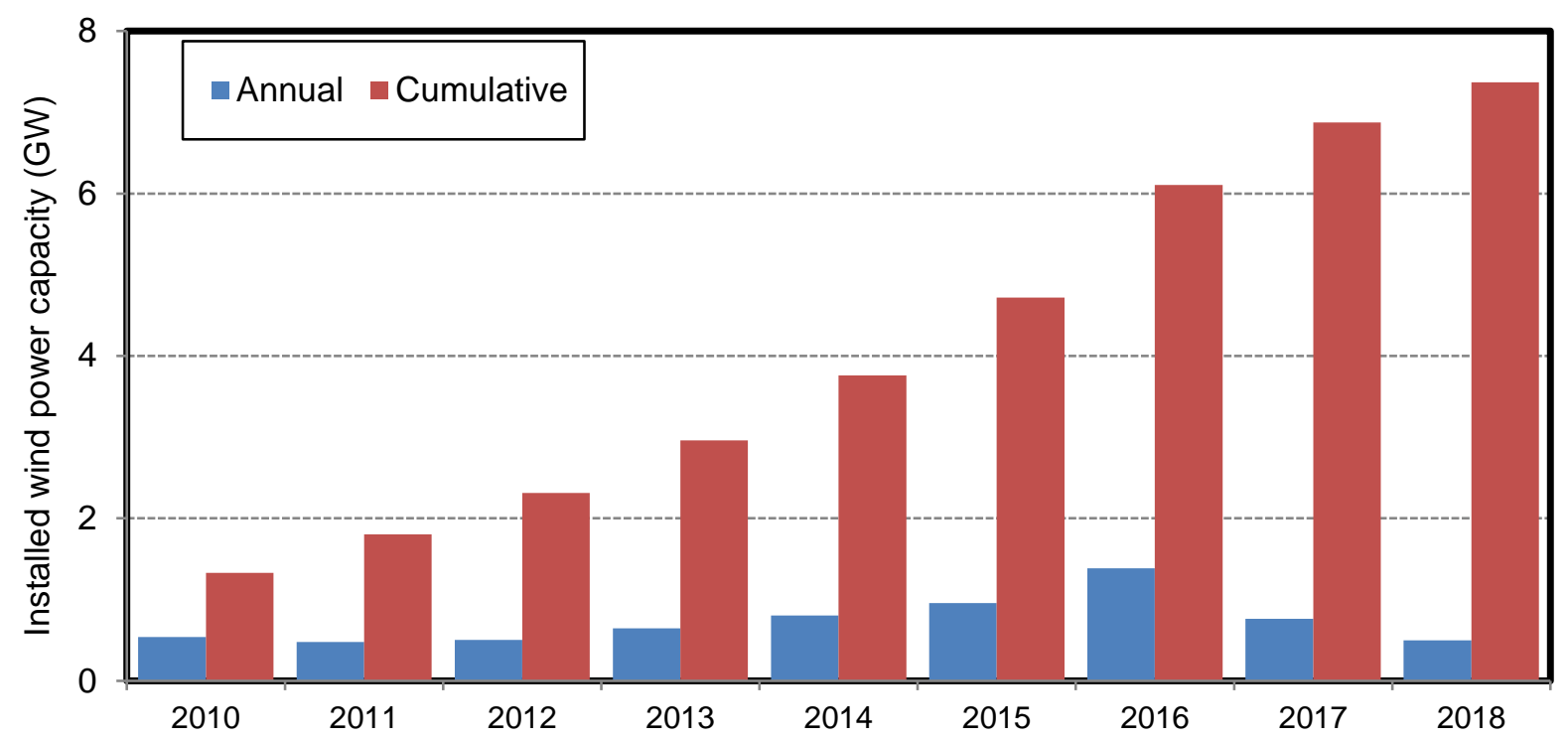

Figure 7. Turkey's annual and cumulative wind power installed capacity

Turkey's cumulative wind power installed capacity is reported in Figure 7 including the years from 2010 to 2018. Capacity of wind energy installation trend rose rapidly within this range of years. In Turkey, the total wind power installed capacity in 2005 and 2010 are stated to be $20 \mathrm{MW}$ and $1.329 \mathrm{MW}$, respectively, denoting the rapid increase in seven years. In upcoming years, 2012, 2013 and 2014, this reaches 2,312 MW, 2,958 MW and 3,762 MW, respectively. By the end of 2018, as wind energy installations came up with 7,369 MW in total, $497 \mathrm{MW}$ of new capacity was introduced to the existing wind power plants [51].

\subsection{Regional Potential Visibility Assessment (PVA) of Wind Turbines}

Wind turbines, either individual or located in wind farms, are generally considered separate from any other developments in the region. In terms of the landscape, there is a need for an interdisciplinary methodology that integrates both quantitative and qualitative approaches to geographic information system-based environmental impact assessment. In this regard, the potential visibility assessment is part of the environmental impact assessment defined in the series of changes in landscape appearance due to turbine technological developments. 
Wind is somewhat regarded as a clean source of energy due to environmental benefits that it provides such as zero $\mathrm{CO}_{2}$ emissions. People generally favor wind power. However, development of wind power throughout the world has resulted with the emergence of some environmental concerns about noise pollution, threats to wildlife and impacts on the visibility. Visibility stand in the forefront of these concerns since high numbers of very tall structures affect the landscape scenery. It is worth to mention that there is no universal judgement of being in favor of or against the presence of wind turbines in scenery. People's perception about the visibility wind turbines may vary between communities or recreational users. This perception also depends on the fact that whether or not wind turbines are in the sight of local dwellers. Jones and Eiser [52] note that local opposition to onshore wind development is on the rise. Their results indicate that people are most favourable to distant offshore development and least favourable to nearby development. They point out that the attitudes to nearby onshore development indicate that so long as a proposed location is anticipated to be 'out of sight' it may be considered relatively acceptable. In this section, changes in the potential visibility of wind turbines in Turkey are discussed. In this discussion visibility is considered as a variable that is proportionate to changes in the number and size (rotor and hub) of the turbines.

\section{Growth in Scale of Wind Turbines}

Turbine sizes have increased significantly in accordance with technological advancements. In this process, the fact that taller turbines with larger blades can use a larger part of the existing wind resource has led to increases in power generation capacity. Capacity of a contemporary on-shore wind turbine varies between 1.5-3 MW. Heights of such turbines are 60-80 m, while a rotor diameters are 60-90 m.

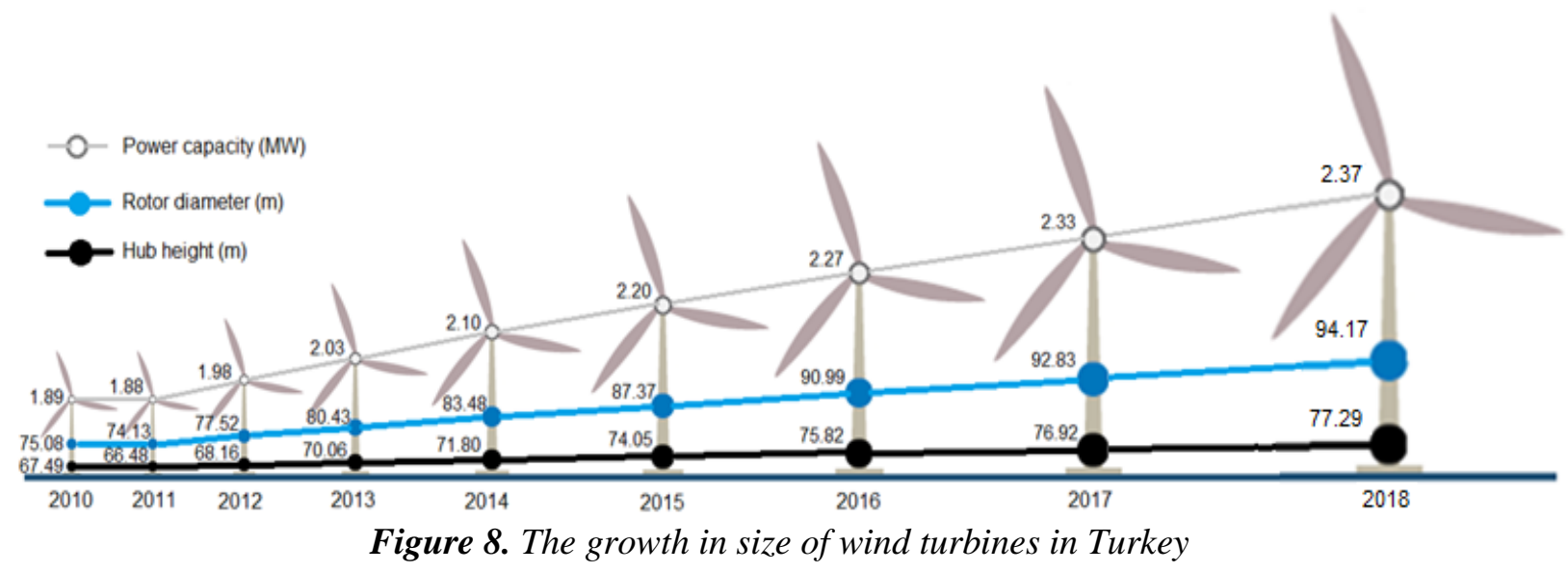

Wind power generation has developed rapidly in Turkey over the recent years. This technology has now formed an increasingly important part of country's electricity industry. Scales of wind farms has been also increasing. The first wind turbine (Vestas $55 \mathrm{~kW}$ ) was installed in 1985 in Çeşme, Izmir province of Turkey. However, the installation of commercial wind turbines dates back to 1998. Three Enercon E-40 wind turbines $(500 \mathrm{~kW}$ each) were installed in Alaçatı, Izmir. Wind energy has shown an unprecedented development in Turkey since 2010. Between 2010 and 2018, installation of advanced power generators with higher hub heights and larger rotor diameters led to increase of wind power generation capacity. Figure 8 shows the growth of wind turbines in Turkey in this period. As depicted in Figure 8, average power capacity of installed onshore wind turbines in 2010 was approximately $1.89 \mathrm{MW}$. This average increased by $25.4 \%$ and reached to $2.37 \mathrm{MW}$ in 2018. Rotor diameters also increased in this period. Average rotor diameter increased by $25.4 \%$ from 75.08 to $94.17 \mathrm{~m}$ similarly, average hub height increased by $14.5 \%$ from 67.49 to $77.29 \mathrm{~m}$. 


\section{Regional Growth in Wind Power Capacity}

Installed onshore wind power capacity of Turkey is 7,369 MW. This capacity is provided by a total number of 3,112 grid-connected wind turbines across 7 geographical regions of the Country. Figure 9 presents the operational wind power plants according to provinces in Turkey [53]. As seen from the figure, Izmir province $(1,426.2 \mathrm{MW})$ has the highest installed capacity of wind farms, with $19.35 \%$ of total wind turbine installations. Bal1kesir (1,123.25 MW, 15.24\% of total installations), Manisa (669.95 MW, 9.09\%), Hatay (364.5 MW, 4.95\%), and Çanakkale (362.8 MW, 4.92\%) are other leading provinces in terms of the installed wind power capacity.

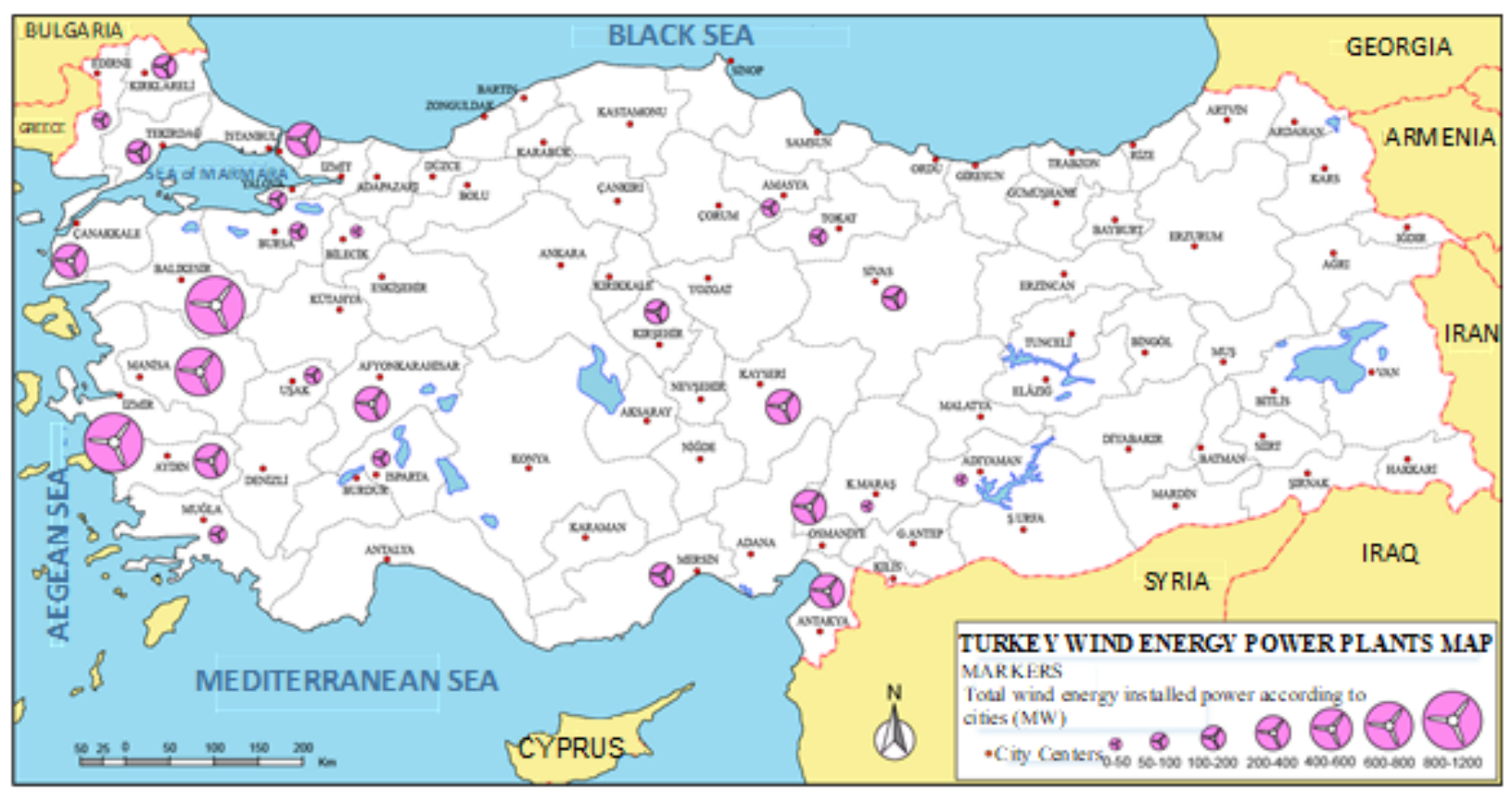

Figure 9. Operational wind power plants according to provinces in Turkey [53]

Çanakkale, Izmir, Balıkesir, and Hatay basins have excellent wind power potential. Marmara, Aegean, (partially) Mediterranean regions are the regions where wind power plant are concentrated. Figure 10 shows growth of wind power capacity according to geographical regions. As seen in this figure, cumulative installed wind turbine capacity increased from 1,329 to 7,369 MW between 2010 and 2018. Growing competence for wind energy, advances in wind power generator technologies, and government policies have played central role in this process. With regard to the geographic regions, largest installed capacities existed in Aegean, Marmara and Mediterranean regions as large as 2,832, 2,449 and $996 \mathrm{MW}$, respectively, as of 2018 [46,51]. 


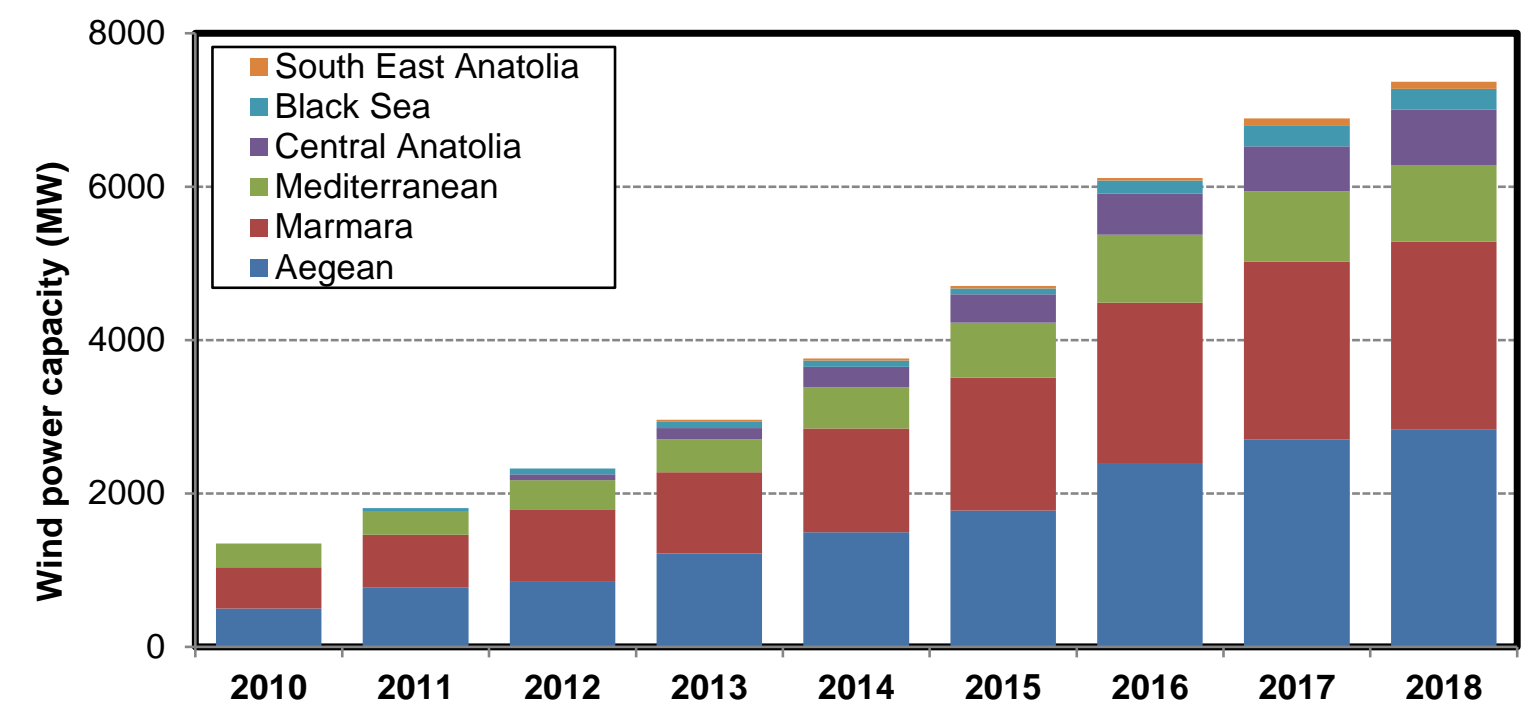

Figure 10. The regional growth in wind power capacity in Turkey

\section{Regional Increase in the Number of Wind Turbines}

Numbers of turbines in power plants may vary from few to over hundred. Nevertheless, sometimes one or two stand-alone turbines can be seen. The visual impact in the landscape is strongly correlated with turbine numbers. In other words, the more turbines exist in scenery, the stronger the impact they create. Not to mention, topography, turbine size and spatial juxtaposition, spatial composition of other landscape elements also determine this impact. Figure 11 shows the regional growth in the number of wind turbines in Turkey since 2010. The total number of wind turbines in Turkey has grown from 714 in 2010 to 3,112 in 2018.

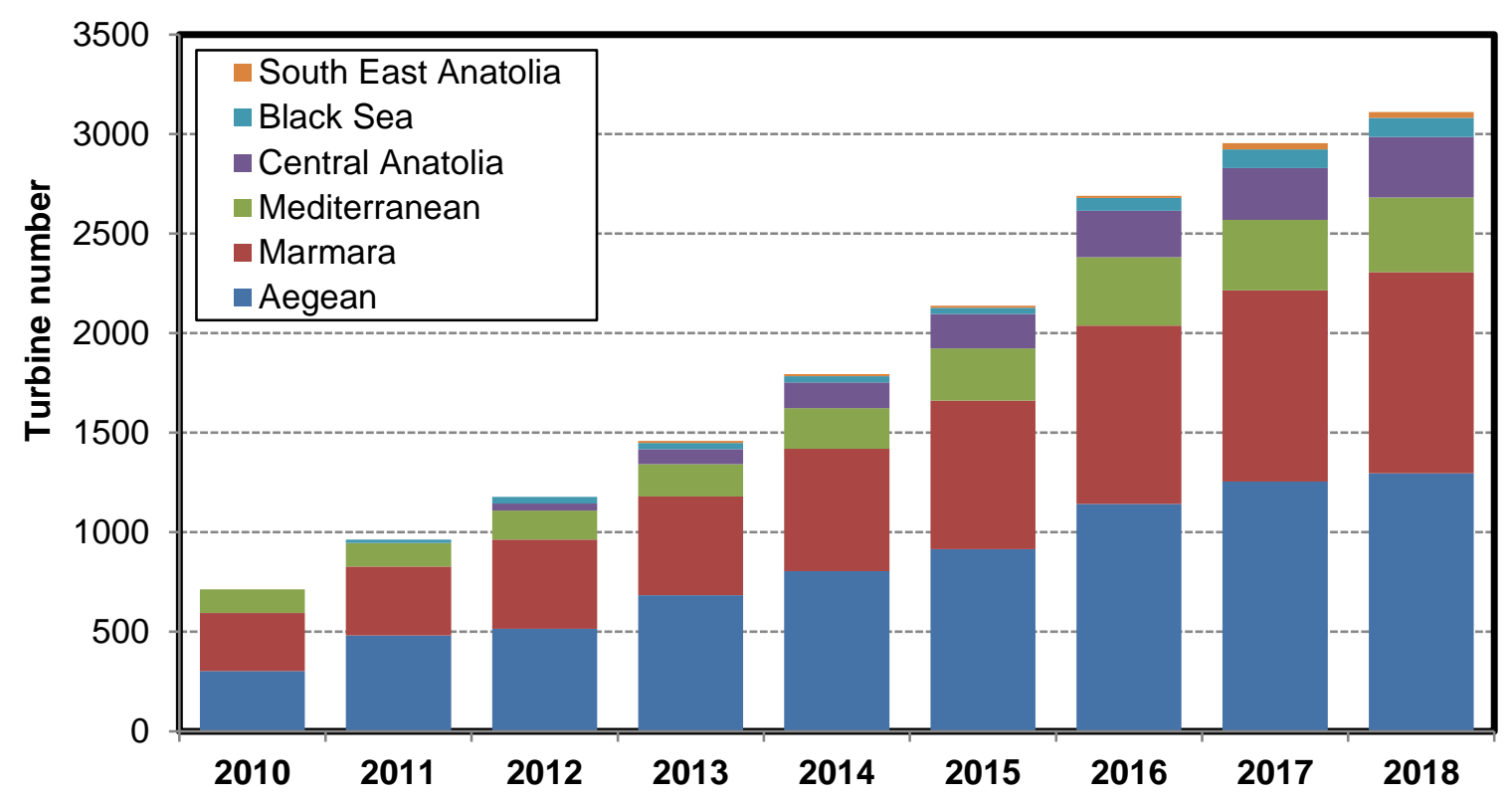

Figure 11. The regional growth in the number of wind turbines in Turkey

Currently, there are 3,112turbines in 180 wind farms in Turkey capable of generating 7,369 MW of energy. As far as the turbine numbers are concerned, largest number of turbines $(1,296)$ exist in the Aegean region. This region is followed by Marmara, Mediterranean, Central Anatolia, Black Sea and Southeast Anatolia Regions with 1,011,375, 304, 96 and 30 turbines, respectively. The number of wind turbines and also farms in Turkey is set to increase dramatically over the next decade according to government policies that promote renewable energy sources. This development may also be regarded as an indicator that the visibility of wind 
turbines and, hence, their visual impact in landscapes will come to the fore and be an increasingly important concern for public.

\section{Regional Growth in Rotor Swept Area and Hub Height of Wind Turbines}

Figures 12 and 13 present the regional growth in the rotor swept area and hub height of wind turbines in Turkey since 2010. As depicted in these figures, the total rotor swept area of wind turbines has grown from 3.43 to $22.83 \mathrm{~km}^{2}$. Total hub heights has also increased from $48.20 \mathrm{~km}$ to $240.53 \mathrm{~km}$. Similar to the regional growth in the numbers, the major growth in the rotor swept area and hub height of wind turbines occurred in the Aegean Region.

The total rotor swept areas of wind turbines in the Aegean Region, Marmara Region, Mediterranean Region, Central Anatolia Region, Black Sea Region and South East Anatolia Region were determined as 8.28, 7.27, 3.21, 2.81, 0.96 and 0.32 square kilometers, respectively. On the other hand, total hub heights were calculated as $95.01,78.40,29.38,26.31,8.39$ and $3.05 \mathrm{~km}$, respectively. This increase in the rotor swept area and hub height of wind turbines has pushed up potential visibility on the landscape of the regions considerably.

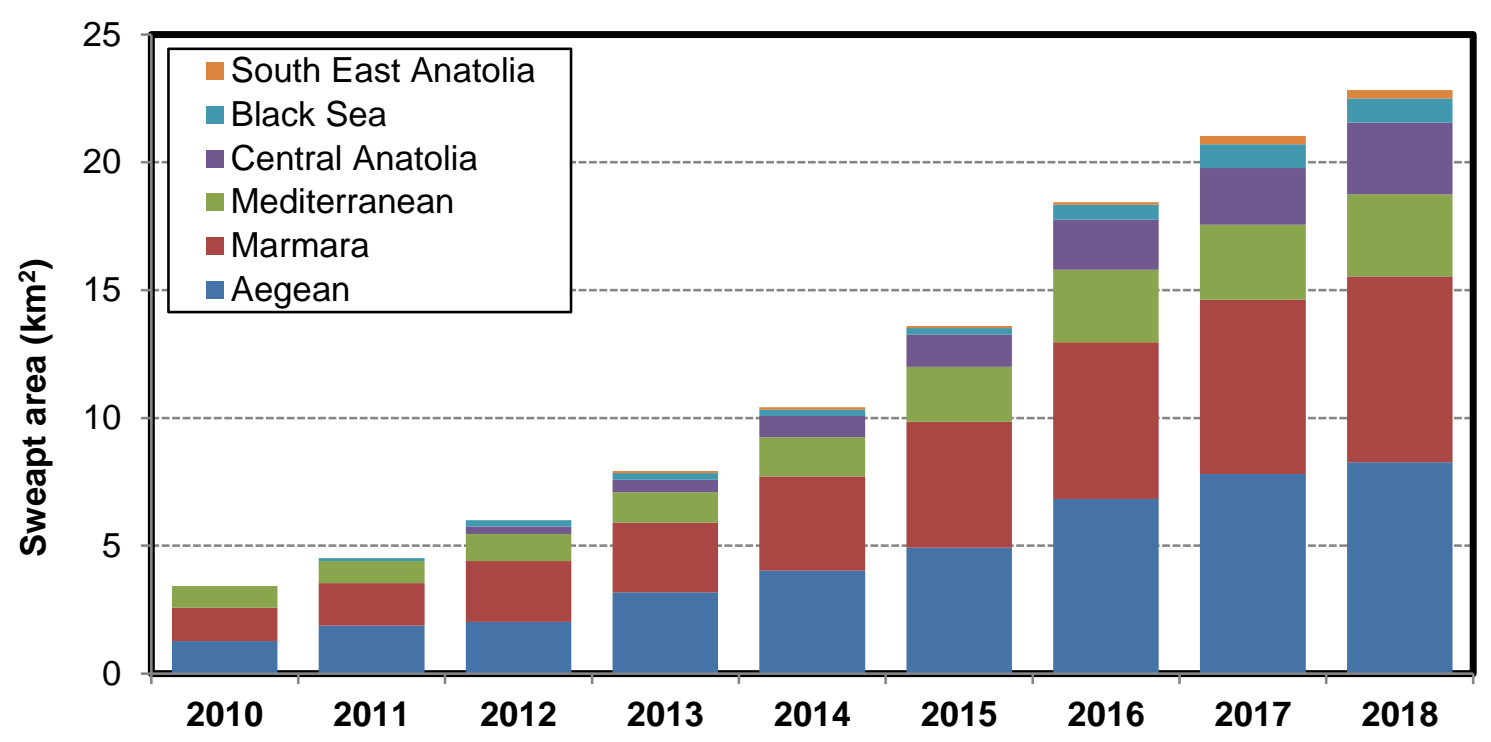

Figure 12. The regional growth in the total rotor swept area of wind turbines in Turkey

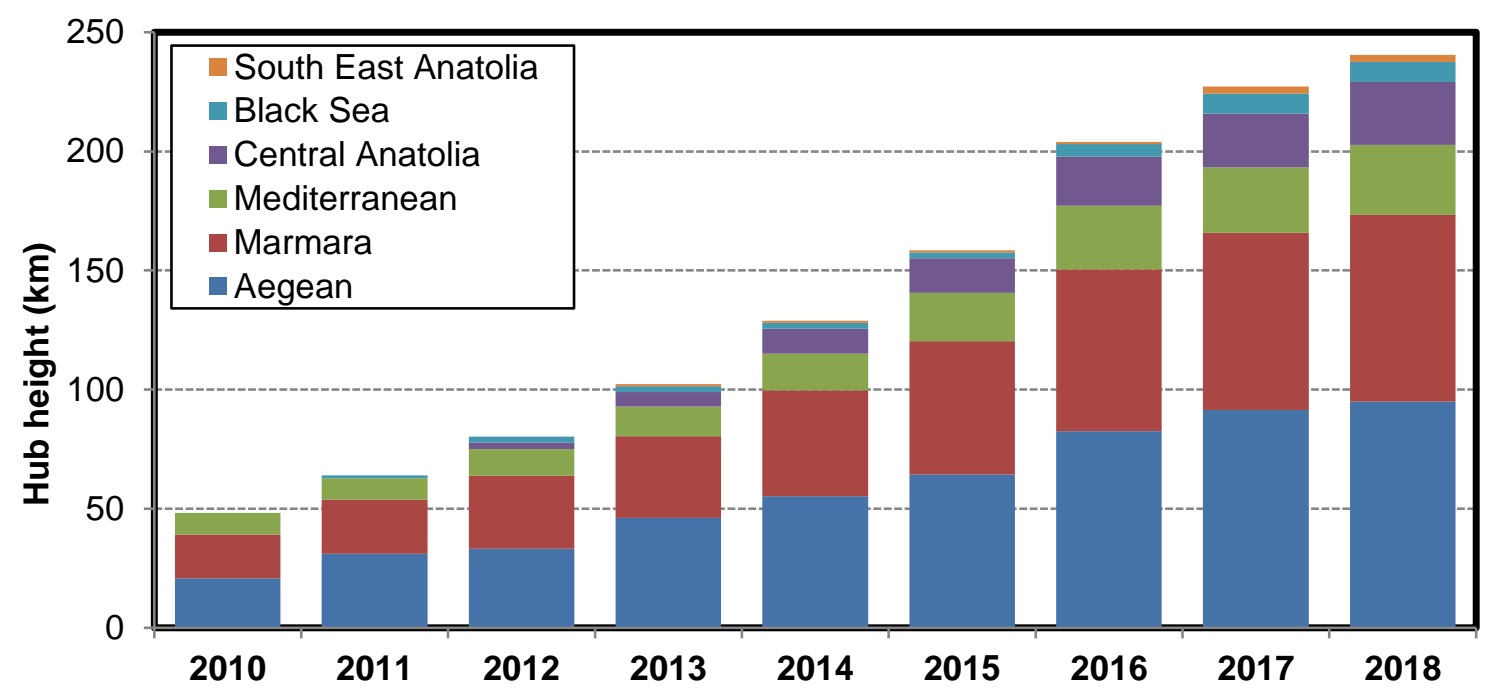

Figure 13. The regional growth in the total hub height of wind turbines in Turkey 


\section{Potential Visibility Results per Power Capacity}

Today in the world, the most general trend in designing wind turbine technologies has been to increase the hub height, the rotor sweep area and the power capacity of the turbines, thereby to reduce turbine cost by improving turbine efficiency. On average, however, the hub height and the rotor swept area of the turbines have grown more rapidly than their power capacities. In Turkey, wind turbines in the latest turbine technology models have larger rotor swept area that can use more wind and thus generate more electricity, bringing down the cost of renewable energy production. Therefore, these wind turbines are becoming more powerful.

Figure 14 shows the regional growth in the rotor swept area per power capacity since 2010 . The figure reveals that the rotor swept area per power capacity have increased significantly. In other words, the swept area of a wind turbine with a rated output capacity of $1 \mathrm{MW}$ has been increased since 2011. This increase in the rotor swept area per power capacity, or ratio of total rotor swept area of the turbines to total power capacity of the turbines, has pushed up turbine power output and also power coefficient for the same wind speeds considerably, since the power output of a wind turbine is directly related to the rotor swept area. The larger the rotor swept area, the more power output it is capable of extracting from the wind. Since larger wind turbines are usually able to deliver electricity at a lower cost than smaller wind turbines, this increase in the rotor swept area of the turbines, in addition, has led to the reduction of energy costs in Turkey. On the other hand, contrary to this positive development, this increase in the rotor swept area per power capacity or larger turbine on the horizon has led to a significant potential visibility or visual impact in landscapes in Turkey. Average swept area for each $1 \mathrm{MW}$ power output from wind turbines was 2,549.59 $\mathrm{m}^{2}$ in 2010, while it increased to $3,101.6 \mathrm{~m}^{2}$ in 2018. Since rotor swept area is one of the strongest visibility variables, increasing trend of this metric in Figure 14 can be considered as a robust indicator that visibility of wind turbines increased.

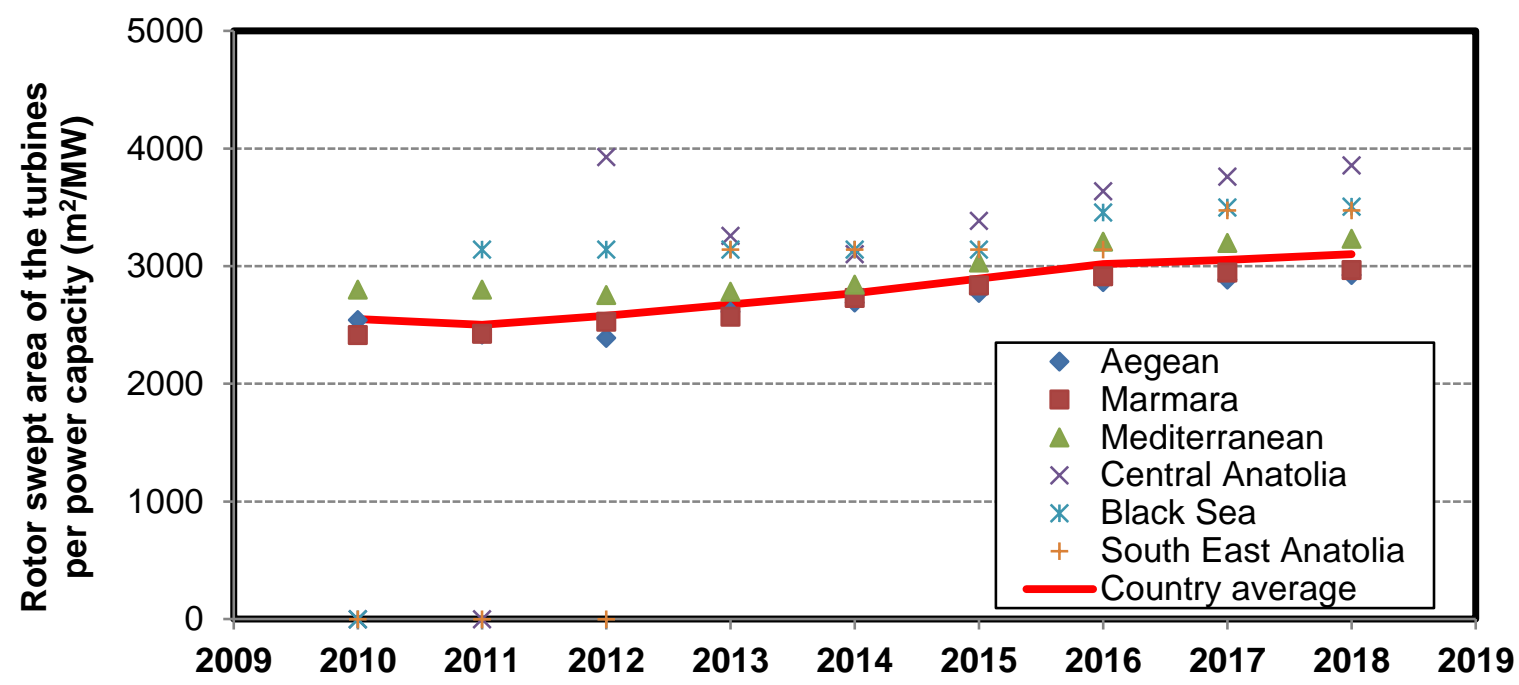

Figure 14. The regional growth in the rotor swept area per power capacity

Number of turbines is also a simple but important metric in terms of visibility, since increase of the number of turbines results with a more likely occurrence of these structures in landscape scenery. All other variables such as hub height or rotor diameters being equal, any positive or negative change in the number of turbines affect landscape visibility correspondingly. Changes in the number of the turbines per power capacity since 2010 is given in Figure 15. As shown in this figure, number of turbines per power capacity has declined since 2010. Growing rotor swept area of the wind turbines has helped to reduce number of turbines required to produce a certain amount of energy. As a result, number of the turbines required to produce each $1 \mathrm{GW}$ of wind energy significantly decreased from 531 to 423 between 2010 and 2018 . Calculated values for this metric should be interpreted carefully in terms of its impact on visibility. Decrease of this metric may suggest less visibility per power capacity. However, it does not necessarily mean that abundance of wind 
turbines has diminished. In fact, it is the number and size of turbines that determine occurrence and visual impact of these structures in landscapes.

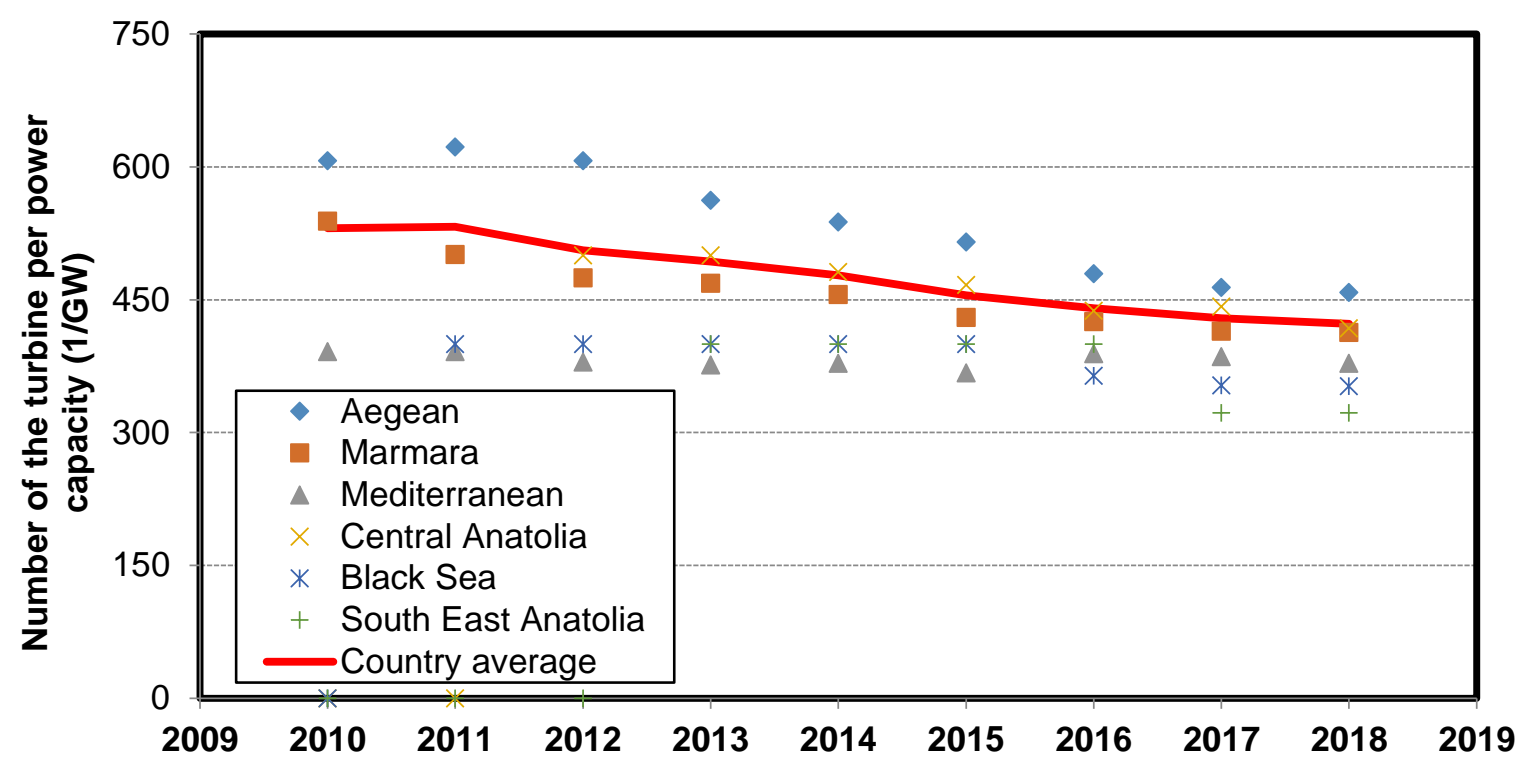

Figure 15. The regional decline in the number of the turbine per power capacity

Figure 16 presents the regional decline in the hub height of the turbine per power capacity since 2010 . It can be seen from the figure that the regional decline in the hub height of the turbine per power capacity is similar to regional decline in the number of the turbine. For example, the hub height of the turbine per power capacity of $1 \mathrm{MW}$ decreased from $35.82 \mathrm{~m}$ in 2010 to $32.68 \mathrm{~m}$ in 2018 .

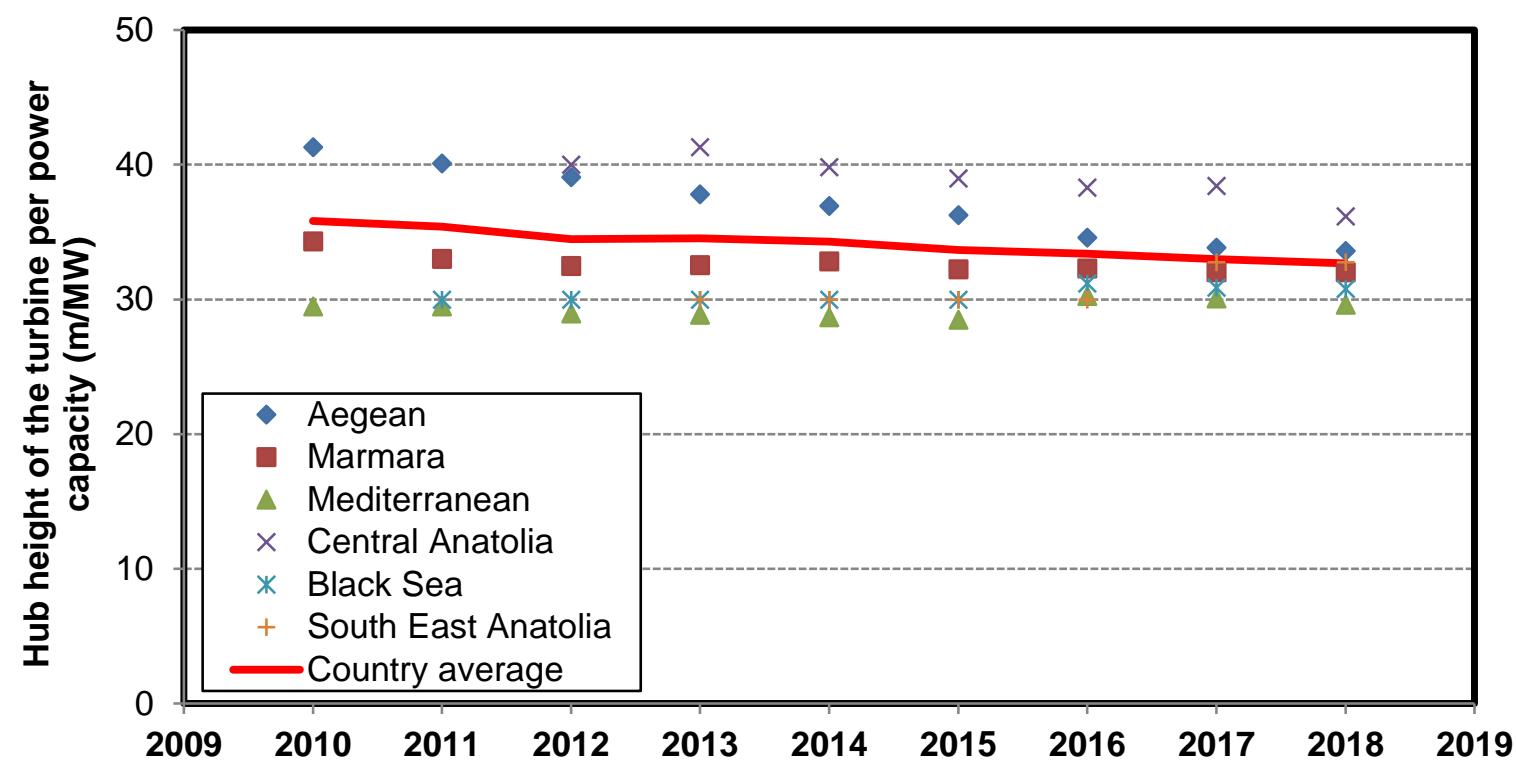

Figure 16. The regional decline in the hub height of the turbine per power capacity

\section{CONCLUSION}

In this study, the regional potential visibility of the wind turbines installed in Turkey was determined. The technological development of the wind turbines, wind power potentiality, techno-economic feasibility, physical appearance, and technical characteristics of onshore wind turbines were evaluated in detail. The results obtained from the study are summarized as follows: 
- Total number of turbines and wind farms in Turkey has increased rapidly over the years and continues to increase.

- Most of the wind turbines in Turkey forming visual impact on the landscape are located in the Aegean region, then in the Marmara Region, the Mediterranean Region, the Central Anatolia Region, the Black Sea Region, and the South East Anatolia Region, respectively.

- The increase in the rotor swept area and a hub height of wind turbines in Turkey has pushed up potential visibility on the landscape of the regions considerably.

- In Turkey, wind turbines in the latest turbine technology models have larger rotor swept area that can use more wind and thus generate more electricity, bringing down the cost of renewable energy production.

- The growing rotor swept area of the wind turbines in Turkey has helped having less number of the turbines and smaller hub heights of the turbines in any farm.

- Increase in the rotor swept area of the turbine per power capacity has pushed up turbine power output and also power coefficient for the same wind speeds considerably.

- As a result, a potential visibility model (PVM) should be developed as an auxiliary variable to control turbine visibility during site-selection for industrial wind power generation projects.

\section{ACKNOWLEDGMENTS}

The authors wish to thank to the Turkish Scientific and Technological Research Council (TUBITAK) for funding this project under Grant No. 2170287.

\section{CONFLICTS OF INTEREST}

No conflict of interest was declared by the authors.

\section{REFERENCES}

[1] IEA, International Energy Agency. Energy statistics manual, https://www.iea.org. Access date 25.08.2018

[2] Waewsak, J., Landry, M., Gagnon, Y., "Offshore wind power potential of the gulf of Thailand", Renewable Energy, 81: 609-626, (2015).

[3] Kaplan, Y.A., "Overview of wind Energy in the world and assessment of current wind energy policies in Turkey", Renewable and Sustainable Energy Reviews, 43: 562-568, (2015).

[4] Bilgili, M., Ozbek, A., Sahin, B., Kahraman, A., "An overview of renewable electric power capacity and progress in new technologies in the World", Renewable and Sustainable Energy Reviews, 49: 323-334, (2015).

[5] Korompili, A., Wu, Q., Zhao, H., "Review of VSC HVDC connection for offshore wind power integration", Renewable and Sustainable Energy Reviews, 59: 1405-1414, (2016).

[6] Emmanouil, G., Galanis, G., Kalogeri, C., Zodiatis, G., Kallos, G., "10-Year high resolution study of wind, sea waves and wave energy assessment in the Greek offshore areas", Renewable Energy, 90: 399-419, (2016).

[7] Söderholm, P., Pettersson, M., "Offshore wind power policy and planning in Sweden", Energy Policy, 39: 518-525, (2011).

[8] IRENA, International Renewable Energy Agency. Renewable energy benefits: measuring the economics, http://www.irena.org. Access date 25.08.2018 
[9] IEA, International Energy Agency. Technology roadmap, Carbon capture and storage, https://www.iea.org. Access date 25.08.2018.

[10] IEA, International Energy Agency. Energy technology perspectives, https://www.iea.org. Access date 25.08.2018

[11] IEA, International Energy Agency. Technology roadmap, wind energy, https://www.iea.org. Access date 25.08.2018

[12] IEA, International Energy Agency. Carbon capture and storage, the solution for deep emissions reductions, https://www.iea.org. Access date 25.08.2018

[13] Zheng, C.W., Li, C.Y., Pan, J., Liu, M.Y., Xia, L.L., "An overview of global ocean wind energy resource evaluations", Renewable and Sustainable Energy Reviews, 53: 1240-1251, (2016).

[14] IRENA-GWEC, International Renewable Energy Agency-Global Wind Energy Council. 30 years of policies for wind energy, http://www.irena.org. Access date 25.08.2018

[15] Liu, T.Y., Tavner, P.J., Feng, Y., Qiu, Y.N., "Review of recent offshore wind power developments in China", Wind Energy, 16: 786-803, (2013).

[16] Dhanju, A., Firestone, J., Kempton, W., "Potential role of power authorities in offshore wind power development in the US", Energy Policy, 39: 7025-7035, (2011).

[17] Chen, J., "Development of offshore wind power in China", Renewable and Sustainable Energy Reviews, 15: 5013-5020, (2011).

[18] IRENA, International Renewable Energy Agency. Wind power technology brief, http://www.irena.org. Access date 25.08.2018.

[19] Abromas, J., "Assessment of the visual impact of wind turbines on the landscape", Summary of Doctoral Dissertation, Technological Sciences, Environmental Engineering (04T), Kaunas University of Technology, Lithuanian Energy Institute, 2014, Kaunas.

[20] Jombach, S., Drexler, D., Sallay, Á., "Using GIS for visibility assessment of a wind farm in Perenye, Hungary", Peer Reviewed Proceedings of Digital Landscape Architectura, Chapter: Conference paper, Publisher: Herbert Wichmann Verlag im Verlag VDE GmbH, Editors: Buhmann, Pietsch, Kretzler, 322-331, (2015).

[21] Tsoutsos, T., Tsouchlaraki, A., Tsiropoulos, M., Kaldellis, J., "Visual impact evaluation methods of wind parks: Application for a Greek Island”, Wind Engineering, 33: 83-92, (2009).

[22] Tsoutsos, T., Tsouchlaraki, A., Tsiropoulos, M., Serpetsidakis, M., "Visual impact evaluation of a wind park in a Greek island”, Applied Energy, 86: 546-553, (2009).

[23] Katsaprakakis, D. A., "A review of the environmental and human impacts from wind parks. A case study for the Prefecture of Lasithi, Crete", Renewable and Sustainable Energy Reviews, 16: 28502863, (2012).

[24] Gibbons, S., "Gone with the wind: Valuing the visual impacts of wind turbines through house prices", Journal of Environmental Economics and Management, 72: 177-196, (2015).

[25] Bishop, I.D., Miller, D.R., "Visual assessment of off-shore wind turbines: The influence of distance, contrast, movement and social variables", Renewable Energy, 32: 814-831, (2007). 
[26] Maehr, A.M., Watts, G.R., Hanratty, J., Talmi, D., "Emotional response to images of wind turbines: A psychophysiological study of their visual impact on the landscape", Landscape and Urban Planning, 142: 71-79, (2015).

[27] Molnarova, K., Sklenicka, P., Stiborek, J., Svobodova, K., Salek, M., Brabec, E., "Visual preferences for wind turbines: Location, numbers and respondent characteristics", Applied Energy, 92: 269-278, (2012).

[28] Svobodova, K., Sklenicka, P., Molnarova, K., Salek, M., "Visual preferences for physical attributes of mining and post-mining landscapes with respect to the sociodemographic characteristics of respondents", Ecological Engineering, 43: 34-44, (2012).

[29] Betakova, V., Vojar, J., Sklenicka, P., "Wind turbines location: How many and how far?", Applied Energy, 151: 23-31, (2015).

[30] Maslov, N., Claramunt, C., Wang, T., Tang, T., "Evaluating the visual impact of an offshore wind farm", Energy Procedia, 105: 3095-3100, (2017).

[31] Maslov, N., Claramunt, C., Wang, T., Tang, T., "Method to estimate the visual impact of an offshore wind farm", Applied Energy, 204: 1422-1430, (2017).

[32] Corry, R. C., "A case study on visual impact assessment for wind energy development", Impact Assessment and Project Appraisal, 29: 303-315, (2011).

[33] Wang, Q., M'Ikiugu, M.M., Kinoshita, I., "Visual impact evaluation of wind farms: a Case Study of Choshi City, Japan", Civil and Environmental Research, 3: 97-107, (2013).

[34] Chias, P., Abad, T., "Wind farms: GIS-based visual impact assessment and visualization tools", Cartography and Geographic Information Science, 40: 229-237, (2013).

[35] Wrozynski, R., Sojka, M., Pyszny, K., "The application of GIS and 3D graphic software to visual impact assessment of wind turbines", Renewable Energy, 96: 625-635, (2016).

[36] Maehr, A. M., Watts, G. R., Hanratty, J., Talmi, D., "Emotional response to images of wind turbines: A psychophysiological study of their visual impact on the landscape", Landscape and Urban Planning, 142: 71-79, (2015).

[37] Minelli, A., Marchesini, I., Taylor, F.E., De Rosa, P., Casagrande, L., Cenci, M., "An open source GIS tool to quantify the visual impact of wind turbines and photovoltaic panels", Environmental Impact Assessment Review, 49: 70-78, (2014).

[38] Skenteris, K., Mirasgedis, S., Tourkolias, C., "Implementing hedonic pricing models for valuing the visual impact of wind farms in Greece", Economic Analysis and Policy, 64: 248-258, (2019).

[39] Bernetti, I., Bambi, L., Barbierato, E., Borghini, T., Capecchi, I., "A decision support system for assessing the perception and acceptance of WTs in high-value landscapes: The case of Chianti Classico (Italy)", Aestimum, 76(1): 19-42, (2020).

[40] Corry R. C., "A case study on visual impact assessment for wind energy development" Impact Assessment and Project Appraisal, 29(4): 303-315, (2011).

[41] Lothian, A., "A survey of the visual impact and community acceptance of wind farms in Australia", Australian Planner, 56(3): 217-227, (2020). 
[42] Abromas, J., Virbašienè, J.K., Ziemeḷniece, A., "Visual impact assessment of wind turbines and their farms on landscape of Kretinga region (Lithuania) and Grobina townscape (Latvia)", Journal of Environmental Engineering and Landscape Management, 23(1): 39-49, (2015).

[43] Bilgili, M., Tontu, M., Sahin, B., "Aerodynamic rotor performance of a 3300-kW modern commercial large-scale wind turbine installed in a wind farm", Journal of Energy Resources Technology, 143: 031302, (2021).

[44] Bilgili, M., Ekinci, F., Demirdelen, T., "A comparison of the performance characteristics of large 2 MW and 3 MW wind turbines on existing onshore wind farms", Wind and Structures, 32(2): 81$87,(2021)$.

[45] REN21, Renewable Energy Policy Network for the 21st Century, Global status report, http://www.ren21.net. Access date 10.07.2019.

[46] GWEC, Global Wind Energy Council, Global wind report, http://www.gwec.net. Access date 10.07.2019

[47] Bilgili, M., Sahin, B., "Electric power plants and electricity generation in Turkey", Energy Sources, Part B: Economics, Planning, and Policy, 5: 81-92, (2010).

[48] Sahin, A.D., "A Review of research and development of wind energy in Turkey", Clean-Soil Air Water, 36: 734-742, (2008).

[49] Bilgili, M., "A global review of wind power installations and their development in Turkey", CleanSoil Air Water, 37: 195-202 (2009).

[50] IEA, International Energy Agency. Energy policies of IEA countries, https://www.iea.org. Access date 25.08.2018

[51] TWEA, Turkish Wind Energy Association, http://www.tureb.com.tr/bilgi-bankasi/turkiye-resdurumu. Access date 10.07.2019

[52] Jones, C.R. and Eiser, J.R., "Understanding 'local' opposition to wind development in the UK: How big is a backyard?", Energy Policy, 38: 3106-3117, (2010).

[53] Cografyaharita, Turkey energy generation maps. http://cografyaharita.com/. Access date 10.07.2019 